\title{
EDITORIAL
}

\section{The challenge of measurement in psychiatry: the lifetime accomplishments of Per Bech (1942-2018)}

\author{
Marcelo P. Fleck, ${ }^{1}$ iD Danilo Carrozzino, ${ }^{2}$ Giovanni A. Fava ${ }^{3,4}$ \\ ${ }^{1}$ Departamento de Psiquiatria e Medicina Legal, Universidade Federal do Rio Grande do Sul (UFRGS), Porto Alegre, RS, Brazil. ${ }^{2}$ Dipartimento \\ di Scienze Psicologiche, della Salute e del Territorio, Università degli Studi " G. d'Annunzio" Chieti e Pescara, Chieti, Italy. ${ }^{3}$ Dipartimento di \\ Psicologia, Università di Bologna, Bologna, Italy. ${ }^{4}$ Department of Psychiatry, State University of New York at Buffalo, Buffalo, NY, USA.
}

In spring 2018, the scientific community lost a great psychiatrist, researcher, and human being: Professor Per Bech passed away suddenly after a typical working day.

Per Bech was Professor of Clinical Psychiatry and Head of the Psychiatric Research Unit, Mental Health Centre North Zealand, University of Copenhagen, Denmark. Working initially in psychometrics, and subsequently in clinimetrics, for more than four decades he was undoubtedly one of the most influential scientists in the field.

He was born in Svendborg, Denmark, on January 12, 1942, and obtained his medical degree in 1969 from the University of Copenhagen. At the same University, he specialized in psychiatry and in 1981 defended his doctoral thesis on rating scales for affective disorders. This work (p. 5) ${ }^{1}$ already contained a central concept that would inspire his future studies with rating scales: "Among psychiatrists it is widely held that rating scales have been overgrown with statistical symbols, terms, and tables. Statistical inference has had an important position. In my opinion, however, the statistical analyses used have been epistemological tools rather than ornamental plants, and they have never been conceived as alternatives to ordinary clinical thinking." In 1983, he was awarded the Anna-Monika-Stiftung Prize for his innovative clinical approach to the assessment of depression.

His original and outstanding contributions, particularly to the field of clinical psychiatry, include more than 490 papers published in international peer-reviewed journals and a number of books, five of which were published in English. ${ }^{2-6}$ Two books in particular, Clinical Psychometrics ${ }^{2}$ and Measurement-Based Care in Mental Disorders, ${ }^{3}$ represent his impressive effort to synthesize decades of work dedicated to the study of rating scales. ${ }^{7,8}$ These books contain principles that all psychiatrists should learn about how rating scales can improve not only their research but also their daily clinical practice with patients. In his Preface to Measurement-Based Care in

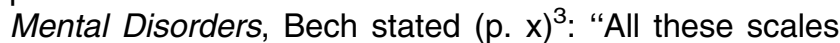
have been used in randomized controlled clinical trials but, as an essential factor in measurement-based care,

Correspondence: Marcelo P. Fleck, Departamento de Psiquiatria e Medicina Legal, Universidade Federal do Rio Grande do Sul (UFRGS), Rua Ramiro Barcelos, 2350, $4^{\circ}$ andar, CEP 90035-003, Porto Alegre, RS, Brazil.

E-mail: mpafleck@gmail.com the scales should also be valid when making a practical outcome evaluation plan in daily clinical routine."

Bech long questioned the adequacy of traditional psychometric theory in clinical psychiatry and psychology. ${ }^{7,9}$ In a 2004 monograph (p. 136), ${ }^{9}$ he stated: "The basic problem with the classical psychometric concept of statistical coherence (as evaluated by Cronbach's coefficient alpha or factor analysis) is what Feinstein has referred to as the psychosocial investigator problem. Such investigators lack the solid clinical experience when they develop their scales and they are therefore fascinated by the coefficients emerging from correlation analyses, often of statistical but not of clinical significance." Professor Bech was one of the first researchers in psychiatry to understand the importance of supplementing the traditional psychometric model with clinimetrics, ${ }^{10}$ the innovative clinically based evaluation method introduced by Alvan $R$. Feinstein ${ }^{11,12}$ and further refined as the science of clinical measurements. ${ }^{13}$ With his groundbreaking studies on clinimetrics, ${ }^{14-19}$ Bech provided a major contribution to the development of this discipline. Combining the clinical judgment of experienced psychiatrists with item response theory (IRT) models, he outlined an innovative method which he used to evaluate the validity of rating scales from a clinimetric perspective. ${ }^{2,4,9,10}$ In his Clinical Psychometrics (p. 48), ${ }^{2}$ Bech stated: "When analyzing the measurement validity of an assessment scale such as, for example, a depression scale, it is important first to evaluate its clinical validity; this can only be done by a highly experienced psychiatrist." Thus, modern IRT models are required to statistically test whether a scale measures the severity of the clinical condition under assessment. ${ }^{2}$ Following such clinimetric principles, ${ }^{20}$ Bech developed a number of fundamental and well-known rating scales, such as the Bech-Rafaelsen Melancholia Scale (MES), ${ }^{21-23}$ the BechRafaelsen Mania Scale (MAS), ${ }^{24-27}$ the World Health Organization-Five Well-Being Index (WHO-5), ${ }^{28-30}$ and the Major Depression Inventory (MDI). ${ }^{31,32} \mathrm{He}$ also modified existing scales and proposed short, clinically incisive
How to cite this article: Fleck MP, Carrozzino D, Fava GA. The challenge of measurement in psychiatry: the lifetime accomplishments of Per Bech (1942-2018). Braz J Psychiatry. 2019;41:369372. http://dx.doi.org/10.1590/1516-4446-2019-0509 
versions of many classical scales, such as the 6-item version of the Hamilton Rating Scale for Depression (HAM-D6), ${ }^{33,34}$ the 6-item version of the Hamilton Rating Scale for Anxiety, ${ }^{3,35}$ and the 6 -item version of the Brief Psychiatric Rating Scale (BPRS). ${ }^{3,14,36}$

Professor Bech also introduced Rasch analysis to clinical psychiatry. He first used the IRT model in a demonstration of the scalability of personality items in 1978. ${ }^{37}$ Three years later, he employed Rasch analysis to demonstrate the clinical validity of the HAM-D6, probably one of the most synthetic rating scales for the assessment of the core symptoms of depression severity. ${ }^{33,38-40}$ In a 2004 paper (p. 135), ${ }^{9}$ he clearly illustrated the clinical utility of Rasch analysis: "In the Rasch analysis, homogeneity is closely linked to transferability. Cattell considered transferability as the key issue in mental testing, and he defined transferability as the extent to which a rating scale measures the same clinical phenomenon in various populations within the range of its intended application (e.g., males versus females, younger versus elderly patients, or primary versus secondary depression)."

Brazilian Journal of Psychiatry readers had the honor of having two contributions by Professor Bech published in the journal. In the 2011 editorial "The ABC profile of the HAM-D17,"41 Bech showed how the 17 items in the HAM-D could be reallocated to follow the vertices of a triangle so that " $A$ " covers the core symptom items of the depressive state (HAM-D6), while "B" (HAM-D9) covers the unspecific stress (arousal) items with reference to Selye's original definition of stress as the non-specific response of the body to any demand made upon it. Finally, "C" (HAMD-2) covers the items of suicidal thoughts and lack of insight. He emphasized that the $A B C$ profile can also be used as a guide to evaluate patients with depressive symptoms, starting from the $B$ vertex, going to the A vertex, and concluding through $C{ }^{41}$ In 2013, Bech was the first author of another study published in the Brazilian Journal of Psychiatry: "The time has come to stop rotations for the identification of structures in the Hamilton Depression Scale (HAM-D17)."42 By changing the pattern of loadings already found clinically meaningful within the principal component analysis approach, Bech and co-authors showed that the rotated factors can be seen as an artifact of factor analysis. ${ }^{42}$ As he previously noted in his Clinical Psychometrics (p. 37) ${ }^{2}$ : "It was after many attempts to perform factor analysis, especially with the many suggested ways of rotation, that Rasch realized that this approach was unscientific, because the guidelines for these rotations procedures were based on trial and error, not on evidence."

In all his innovative initiatives, the patient was the focus of his efforts, and the clinician, besides, benefited from the development of new tools for clinical measurement. In his last book (p. 86), ${ }^{3}$ Bech stressed this concept: "The value of measurement-based care evaluation plans in the daily routine is in taking into account such issues as why do patients so often drop out of the treatment plan? Or why do they stop taking their medicine? We have considered the essential element in measurement-based care as that of ensuring a collaborative relationship between the doctor and his or her patient. The self-reported
Symptom Checklist-90 (SCL-90) subscales, the selfreported side-effect scale (PRISE-CAR), and the WHO-5 well-being questionnaire are measurements that require the doctor to listen to the patient. This makes it possible for the doctor and the patient to collaborate every second week to evaluate the extent of improvement during the course of treatment."

Professor Bech proposed the pharmacopsychometric triangle for measurement-based care. ${ }^{2,3,43}$ In this model, the first vertex of the triangle represents clinically desired effects; the second represents the adverse or side effects of medications; and the third, patient-reported quality of life or psychological well-being. Bech focused on a clinimetric approach and performed the Rasch and Mokken analyses to identify short and valid rating scales to be used for each vertex. ${ }^{2,3,43}$ Using brief, unidimensional, and clinically valid instruments which also display clinimetric sensitivity is an excellent strategy to optimize the time spent during an interview with a patient. ${ }^{3,44}$ Using instruments that are shorter and more user-friendly would allow clinicians to both spend more time in empathic human contact and also measure the care provided.

Recently, Fava et al. ${ }^{45}$ noted that standard psychometric evaluation methods are inadequate to capture the complexity of treatment outcomes in psychopharmacology. Therefore, they proposed a comprehensive assessment strategy and defined as "clinical pharmacopsychology" the area concerned with the application of clinimetric methods to the evaluation of psychological effects of medications, including the clinical benefits of psychotropic drugs, the characteristics that predict responsiveness to treatment, the vulnerabilities induced by specific therapies (i.e., side effects, behavioral toxicity, iatrogenic comorbidity), and the interaction of drugs with specific and nonspecific treatment ingredients. ${ }^{45}$ As they state in their position paper (p. 134), ${ }^{45}$ "Clinical pharmacopsychology offers a unifying framework for the understanding of clinical phenomena in medical and psychiatric settings."

Another area that particularly attracted Bech's attention in recent years was the clinical assessment of positive mental health. $3,46-49$ To evaluate such a clinical dimension, he recommended using rating scales with positively worded items. ${ }^{3,17,44} \mathrm{He}$ and his research group ${ }^{28,29}$ validated one of the most widely used rating scales containing only positively phrased items: the WHO-5, a self-report questionnaire for the assessment of psychological well-being. Recently, Fava et al. ${ }^{50}$ provided a comprehensive definition of positive mental health when they introduced the concept of euthymia. They expanded the traditional meaning of euthymia used in the psychiatric literature and described a condition characterized not only by the absence of affective, disorders but also by the presence of psychological flexibility and well-being, resistance to stress, and a unifying outlook on life, which guides actions and feelings for shaping future accordingly. ${ }^{50}$ They also developed a self-rating scale for the assessment of euthymia, ${ }^{50}$ which has been found to display excellent clinimetric properties. ${ }^{51}$ In his Measurement-Based Care in Mental Disorders (p. 46), ${ }^{3}$ Bech described this scale as follows: "The euthymia scale can be considered a 
combination of the fighting spirit personality and the WHO-5 items."

Professor Bech's work is a legacy of how science and humanism can interact and improve the quality of care. With his mind looking ahead, he anticipated the future challenges for clinician scientists ${ }^{52}$ : applying scientific methods to the care of patients and the assessment of their mental health. ${ }^{53,54}$ Thank you, Professor Bech, for your extraordinary contribution and example.

\section{Disclosure}

The authors report no conflicts of interest.

\section{References}

1 Bech P. Rating scales for affective disorders: their validity and consistency. Acta Psychiatr Scand Suppl. 1981;295:1-101.

2 Bech P. Clinical psychometrics. Nova Jersey: Wiley Blackwell; 2012.

3 Bech P. Measurement based care in mental disorders. New York: Springer; 2016.

4 Bech P. Rating scales for psychopathology, health status and quality of life. New York: Springer; 1993.

5 Bech P. The Bech, Hamilton and Zung Scales for mood disorders: screening and listening. New York: Springer; 1996.

6 Bech P, Coppen A. The Hamilton scales. New York: Springer; 1990.

7 Fava GA, Carrozzino D, Lindberg L, Tomba E. The clinimetric approach to psychological assessment: a tribute to Per Bech, MD (1942-2018). Psychother Psychosom. 2018;87:321-6.

8 Lindberg L, Bech-Andersen G, Søndergaard S, Ellervik C, Østergaard SD, Martiny K. Per Bech 12.1.1942 - 9.5.2018 In Memoriam. Nord J Psychiatry. 2018;72:395.

9 Bech P. Modern psychometric in clinimetrics: impact on clinical trials of antidepressants. Psychother Psychosom. 2004;73:134-8.

10 Tomba E, Bech P. Clinimetrics and clinical psychometrics: macroand micro-analysis. Psychother Psychosom. 2012;81:333-43.

11 Feinstein AR. T. Duckett Jones Memorial Lecture. The Jones criteria and the challenges of clinimetrics. Circulation. 1982;66:1-5.

12 Feinstein AR. An additional basic science for clinical medicine: IV. The development of clinimetrics. Ann Intern Med. 1983;99:843-8.

13 Fava GA, Tomba E, Sonino N. Clinimetrics: the science of clinical measurements. Int J Clin Pract. 2012;66:11-5.

14 Bech P, Austin SF, Timmerby N, Ban TA, Møller SB. A clinimetric analysis of a BPRS- 6 scale for schizophrenia severity. Acta Neuropsychiatr. 2018;30:187-91.

15 Timmerby N, Andersen JH, Søndergaard S, Østergaard SD, Bech P. A systematic review of the clinimetric properties of the 6-item version of the Hamilton Depression Rating Scale (HAM-D6). Psychother Psychosom. 2017;86:141-9.

16 Carrozzino D, Morberg BM, Siri C, Pezzoli G, Bech P. Evaluating psychiatric symptoms in Parkinson's disease by a clinimetric analysis of the Hopkins Symptom Checklist (SCL-90-R). Prog Neuropsychopharmacol Biol Psychiatry. 2018;81:131-7.

17 Timmerby N, Nørholm V, Rasmussen NA, Lindberg L, Andreasson Aamund K, Bech P. A major clinimetric dilemma in self-reported outcome scales: mixing positively and negatively worded items. Psychother Psychosom. 2017;86:124-5.

18 Carrozzino D, Vassend O, Bjørndal F, Pignolo C, Olsen LR, Bech P. A clinimetric analysis of the Hopkins Symptom Checklist (SCL-90-R) in general population studies (Denmark, Norway, and Italy). Nord J Psychiatry. 2016;70:374-9.

19 Timmerby N, Cosci F, Watson M, Csillag C, Schmitt F, Steck B, et al. A confirmative clinimetric analysis of the 36 -item family assessment device. Nord J Psychiatry. 2018;72:268-72.

20 Guidi J, Fava GA, Bech P, Paykel E. The clinical interview for depression: a comprehensive review of studies and clinimetric properties. Psychother Psychosom. 2011;80:10-27.

21 Bech $\mathrm{P}$, Rafaelsen OJ. The use of rating scales exemplified by a comparison of the Hamilton and the Bech-Rafaelsen Melancholia Scale. Acta Psychiatr Scand. 1980;62(Suppl 285):128-32.
22 Bech P. The Bech-Rafaelsen Melancholia Scale (MES) in clinical trials of therapies in depressive disorders: a 20-year review of its use as outcome measure. Acta Psychiatr Scand. 2002;106: 252-64.

23 Licht RW, Qvitzau S, Allerup P, Bech P. Validation of the BechRafaelsen Melancholia Scale and the Hamilton Depression Scale in patients with major depression; is the total score a valid measure of illness severity? Acta Psychiatr Scand. 2005;111:144-9.

24 Bech P, Rafaelsen OJ, Kramp P, Bolwig TG. The mania rating scale: scale construction and inter-observer agreement. Neuropharmacology. 1978;17:430-1.

25 Bech P, Bolwig TG, Kramp P, Rafaelsen OJ. The Bech-Rafaelsen mania scale and the Hamilton depression scale. Acta Psychiatr Scand. 1979;59:420-30.

26 Bech P, Baastrup PC, de Bleeker E, Ropert R. Dimensionality, responsiveness and standardization of the Bech-Rafaelsen mania scale in the ultra-short therapy with antipsychotics in patients with severe manic episodes. Acta Psychiatr Scand. 2001;104:25-30.

27 Bech P. The Bech-Rafaelsen mania scale in clinical trials of therapies for bipolar disorder: a 20-year review of its use as an outcome measure. CNS Drugs. 2002;16:47-63.

28 Topp CW, Østergaard SD, Søndergaard S, Bech P. The WHO-5 Well-Being Index: a systematic review of the literature. Psychother Psychosom. 2015;84:167-76.

29 Bech P, Gudex C, Johansen KS. The WHO (Ten) Well-Being Index: validation in diabetes. Psychother Psychosom. 1996;65:183-90.

30 Bech P, Olsen LR, Kjoller M, Rasmussen NK. Measuring well-being rather than the absence of distress symptoms: a comparison of the SF-36 Mental Health subscale and the WHO-Five Well-Being Scale. Int J Methods Psychiatr Res. 2003;12:85-91.

31 Bech P, Rasmussen NA, Olsen LR, Noerholm V, Abildgaard W. The sensitivity and specificity of the Major Depression Inventory, using the Present State Examination as the index of diagnostic validity. J Affect Disord. 2001;66:159-64.

32 Olsen LR, Jensen DV, Noerholm V, Martiny K, Bech P. The internal and external validity of the Major Depression Inventory in measuring severity of depressive states. Psychol Med. 2003;33:351-6.

33 Bech P, Allerup P, Gram LF, Reisby N, Rosenberg R, Jacobsen O, et al. The Hamilton Depression Scale. Evaluation of objectivity using logistic models. Acta Psychiatr Scand. 1981;63:290-9.

34 Bech $\mathrm{P}$, Wilson $\mathrm{P}$, Wessel $\mathrm{T}$, Lunde $\mathrm{M}$, Fava $\mathrm{M}$. A validation analysis of two self-reported HAM-D6 versions. Acta Psychiatr Scand. 2009;119:298-303.

35 Bech P. Dose-response relationship of pregabalin in patients with generalized anxiety disorder. A pooled analysis of four placebocontrolled trials. Pharmacopsychiatry. 2007;40:163-8.

36 Bech P, Larsen JK, Andersen J. The BPRS: psychometric developments. Psychopharmacol Bull. 1988;24:118-21.

37 Bech P, Allerup P, Rosenberg R. The Marke-Nyman temperament scale. Evaluation of transferability using the Rasch item analysis. Acta Psychiatr Scand. 1978;57:49-58.

38 Lecrubier $\mathrm{Y}$, Bech $\mathrm{P}$. The Ham $\mathrm{D}(6)$ is more homogenous and as sensitive as the Ham D(17). Eur Psychiatry. 2007;22:252-5.

39 Østergaard SD, Bech P, Miskowiak KW. Fewer study participants needed to demonstrate superior antidepressant efficacy when using the Hamilton melancholia subscale $\left(H A M-D_{6}\right)$ as outcome measure. $J$ Affect Disord. 2016;190:842-5.

40 Bech $P$. The responsiveness of the different versions of the Hamilton Depression Scale. World Psychiatry. 2015;14:309-10.

41 Bech P. The ABC profile of the HAM-D17. Braz J Psychiatry. 2011;33:109-10.

42 Bech P, Csillag C, Hellström L, Fleck MP. The time has come to stop rotations for the identification of structures in the Hamilton Depression Scale (HAM-D 17$)$. Braz J Psychiatry. 2013;35:360-3.

43 Bech P. Applied psychometrics in clinical psychiatry: the pharmacopsychometric triangle. Acta Psychiatr Scand. 2009;120:400-9.

44 Bech P. Clinimetric dilemmas in outcome scales for mental disorders. Psychother Psychosom. 2016;85:323-6.

45 Fava GA, Tomba E, Bech P. Clinical pharmacopsychology: conceptual foundations and emerging tasks. Psychother Psychosom. 2017:86:134-40.

46 Bech P. Clinical assessment of positive mental health. In: Jeste DV, Palmer BW. Positive psychiatry. Arlington: American Psychiatric Publishing; 2015. p. 127-43. 
47 Bech $\mathrm{P}$. Through measurement positive care in psychiatry is conquered. Nord J Psychiatry. 2018;72:393-4.

48 Bech P, Lindberg L, Møller SB. The Reliable Change Index (RCI) of the $\mathrm{WHO}-5$ in primary prevention of mental disorders. A measurement-based pilot study in positive psychiatry. Nord J Psychiatry. 2018;72:404-8.

49 Bech P, Carrozzino D, Austin SF, Møller SB, Vassend O. Measuring euthymia within the Neuroticism Scale from the NEO Personality Inventory: a Mokken analysis of the Norwegian general population study for scalability. J Affect Disord. 2016;193:99-102.

50 Fava GA, Bech P. The concept of euthymia. Psychother Psychosom. 2016;85:1-5.
51 Carrozzino D, Svicher A, Patierno C, Berrocal C, Cosci F. The Euthymia scale: a clinimetric analysis. Psychother Psychosom. 2019 Jan 30:1-3. doi: 10.1159/000496230. [Epub ahead of print]

52 Monzer N, Herzog W, Löwe B, Zipfel S, Henningsen P, Rose M, et al. Reviving the clinician scientist: a best practice model. Psychother Psychosom. 2019 Jan 3:1-2. doi: 10.1159/000495693. [Epub ahead of print]

53 Fava GA, Cosci F, Tomba E. Overcoming the crisis of clinical research. Psychother Psychosom. 2018;87:1-4.

54 Engel GL. Physician scientists and scientific physicians. Resolving the humanism-science dichotomy. Am J Med. 1987;82:107-11. 